\title{
STUDIES ON HUMAN CAPILLARIES
}

\section{Observations on the Nature of the Capillary Pulse in AORTIC INSUFFICIENCY}

\author{
By J. HAMILTON CRAWFORD With the TeChNICAL Assistance of \\ H. ROSENBERGER
}

(From the Hospital of the Rockefeller Institute for Medical Research, New York)

(Received for publication April 1, 1927)

The first description of the capillary pulse was given in 1868 by Quincke (1) who observed it in a number of different conditions but stated that it was most manifest in cases of aortic insufficiency. $\mathrm{He}$ thought that the mechanism involved was a true pulsation in the capillaries, that is to say, a pulsatile movement in the capillaries resulting from cardiac systole. The phenomenon has come to be commonly recognized in clinical medicine and until recently it was assumed that it was due to actual pulsation in the capillaries. Since it has been shown, however, that the capillaries can be viewed microscopically the mechanism involved has been studied by several investigators but no agreement has been reached as to its nature. In conditions in which a capillary pulse is present there is apt to be a pulsatile movement of the whole part examined due to the heart beat, and as this takes place at the precise moment when the changes for which one is looking would take place, the greatest care must be observed in carrying out the observations so that in consequence of the motion involved the capillaries do not slip out of focus.

Before the advent of capillary microscopy Herz (2) expressed doubt as to whether pulsation took place in the capillaries and thought rather that it did so in the arterioles. As the result of his microscopic observations of the skin capillaries Jürgensen (3) differentiated two groups of cases; one with a true capillary pulse in which there was an actual pulsation of the stream within the capillaries and the other with a pseudo-capillary pulse in which there was no pulsation of the stream. In the latter the impression of pulsation was given to the capillaries 
of the superficial layers by pulsation transmitted to them by the pulse of deeper lying vessels such as the digital arteries and arterioles. The former he thought was most often present in aortic insufficiency and the latter was seen in many cases of arteriosclerosis. Freedlander and Lenhart (4) as the result of their studies arrived at similar conclusions. Weiss and Dieter (5) described a pulsatile flow in the capillaries in aortic disease while Secher (6), Fischl (7) and HisingerJagerskiöld (8) came to the conclusion that the phenomenon was not due to pulsation of the blood stream within the capillaries. Secher saw pulsation in the capillaries in a few cases of his series but HisingerJagerskiöld only observed it in one of his. Boas (9) studied the capillaries of the nail fold in cases of aortic insufficiency and hypertension and came to the conclusion that the capillary pulse was not a manifestation of pulsation of the capillaries but was due to an exaggerated pulsation of the arterioles and possibly of the venules of the sub-papillary plexus. Sumbal (10) investigated the capillaries of the lip in cases of aortic regurgitation and stated that pulsation could be seen in every case in the capillaries in which the flow was not too rapid. As the result of Sumbal's work Boas (11) reinvestigated the subject and studied the capillaries in various situations. He was able to demonstrate actual pulsation in the capillaries in some patients with aortic insufficiency but he did not think it was present with sufficient constancy or intensity to warrant adopting it as the explanation of clinical capillary pulsation. Lewis (12) has more recently carried out an extensive study of the question. He regarded macroscopic capillary pulsation as a physiological phenomenon which can readily be induced in normal individuals by heating the part examined and thus causing dilatation of the arterioles. He stated that anything which induces arteriolar dilatation will bring about pulsatile flow in the capillaries. He never failed to observe pulsation in the capillaries of any area in which pulsation of color was visible to the naked eye and in which the blood flow in a reasonable number of capillaries could be detected. He thinks that every case, regardless of etiology, in which clinical capillary pulsation, that is to say a change of color, is evident, shows pulsation in the capillaries due to dilatation of the arterioles. When macroscopic pulsation is observable the pulse passes from the arterioles through the capillaries 
to the venules and the pulsation of these plays a greater or lesser part in the color changes observed according to the situation examined. Heimberger (13) found in normal individuals that mechanical irritation of the arterial limb of the capillary or the local application of drugs which dilate them causes pulsation to appear. Pulsation also resulted from light pressure on the venous limb or from heat. He concluded that in normal individuals the pulse wave was most often lost in the arterial limb of the capillaries and could be seen throughout the whole capillary only when the tone of the arterial limb was reduced. To summarize these statements one may say that two views are held as to the main cause of "capillary pulsation" observed in cases of aortic insufficiency: (a) that it is due to pulsation of the blood stream within the capillaries and $(b)$ that it is due to an exaggerated pulsation in the larger vessels which lie deeper.

The results to be reported are based on the study of twelve cases of aortic insufficiency in which there was well marked macroscopic capillary pulsation. Seven of these were of rheumatic origin, four of syphilitic and one was due to subacute bacterial endocarditis. None of the cases showed marked signs of cardiac decompensation. Cinematographic records of the capillaries at the nail fold and electrocardiograms (Lead II) were made simultaneously? Synchronous points were recorded on the cinematographic film and electrocardiograms by means of signals which were operated by a common switch. By this means it was possible to calculate the precise phase of the particular cardiac cycle to which each cinematographic photograph corresponded. The details of the technique of making the cinematographic exposures and the methods employed in their study have been previously described $(14,15)$.

\section{OBSERVATIONS}

Changes in calibre. The average size of both the arterial and venous limbs was similar to that seen in normal subjects. Variations in the diameter took place continuously. The extent of these changes varied from capillary to capillary in the same subject and also from subject to subject. The magnitude of the variations in calibre was greater in the arterial limb in many instances than had been observed 
in normal individuals (fig. 1). The venous limb as a rule showed changes in diameter which corresponded more closely with the normal.

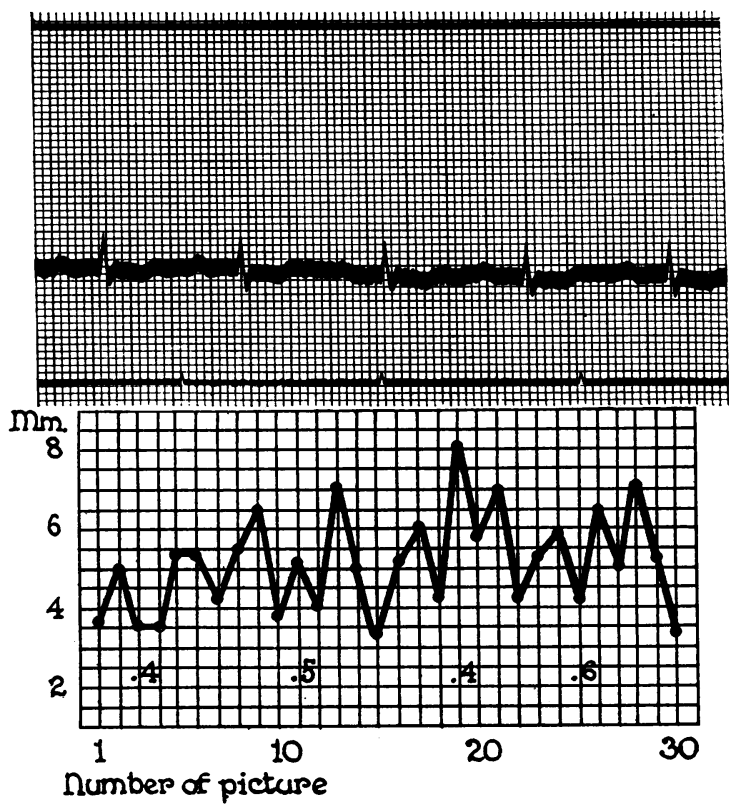

Fig. 1. An Electrocardiogram (Lead II) Is Shown from a Case of Aortic Insufficiency in Which Macroscopic Capillary Pulsation Was Visible

The electrocardiogram was taken at the same time as cinematographic records were made of the capillaries at the nail fold. Synchronous points of the electrocardiograms and of the cinematographic exposures were identified by means of two signals in a single circuit one recording on the electrocardiograph film and the other on the cinematograph film. Underneath the electrocardiogram are shown the changes which took place in the diameter of the arterial limb of a capillary during identical cycles. Each measurement is actually synchronous with the point in the electrocardiogram immediately above it without allowance for the probable transmission time.

The ordinate represents the diameter of the arterial limb in millimeters at a point $2 \mathrm{~cm}$. from the tip of the capillary loop after magnification of the capillary 350 times. The number of cinematographic exposures was 10 per second. The decimal numbers indicate the time in seconds after the onset of ventricular systole (taken as the beginning of the R-wave of the electrocardiogram) at which the maximum diameter of the arterial limb was present in each cardiac cycle.

Evidences of pulsation due to the heart beat. The chief interest in this investigation consists in the study of the relation of the changes 
in the capillaries to the pulse beat, to see whether the capillaries show rhythmic changes in diameter such as would take place if a pulsatory flow of blood were present in the capillaries themselves. Changes took place constantly in both limbs of the capillary loops but as a rule were more marked in the arterial limb. These were, however, totally irregular and showed no rhythmicity such as one would expect if they were due to pulsation of the blood stream in the capillary (fig. 1). If the mechanism involved were of a pulsatory nature there ought to be a constant time relation between the onset of ventricular systole-taken as the beginning of the R-wave of the electrocardio-

TABLE 1

The time in seconds after the onset of ventricular systole at which the maximum diameters of the limbs of the capillary loop occurred

\begin{tabular}{r|c|c}
\hline Cycle & Arterial & Venous \\
\cline { 2 - 3 } I & seconds & seconds \\
II & 0.41 & 0.71 \\
III & 0.57 & 0.27 \\
IV & 0.71 & 0.61 \\
V & 0.31 & 0.11 \\
VI & 0.30 & 0.40 \\
VII & 0.27 & 0.67 \\
VIII & 0.29 & 0.59 \\
IX & 0.63 & 0.53 \\
X & 0.67 & 0.67 \\
XI & 0.41 & 0.51 \\
XII & 0.55 & 0.55 \\
XIII & 0.49 & 0.09 \\
\hline
\end{tabular}

gram-and the occurrence of the maximum diameter of the arterial and possibly also of the venous limb of the capillary. This time was calculated in a large number of cardiac cycles but was not constant so that no evidence of pulsation in the capillaries is afforded by this means (table 1). In a series of cycles which have been measured (table 1) the time varied in the case of the arterial limb from 0.27 to 0.71 second and in the venous limb from 0.09 to 0.71 second. In one subject the flow of blood in the capillary was frequently interrupted so that the length of the arterial limb in which blood was visible varied constantly. On superficial examination it looked as if 
pulsation were present. The length of the arterial limb in a large series of consecutive photographs was traced and studied in conjunction with the electrocardiogram. If the changes were due to pulsation there ought to have been a rhythmic filling and emptying of the arterial limb. Most blood ought to have been visible in it at a constant

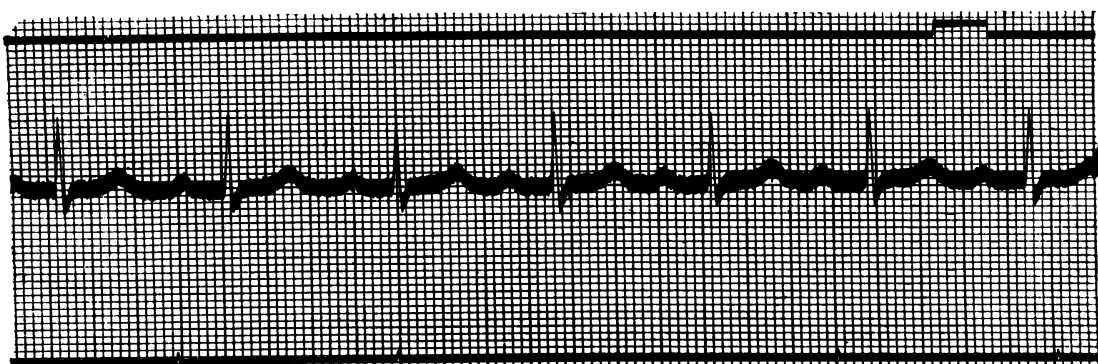

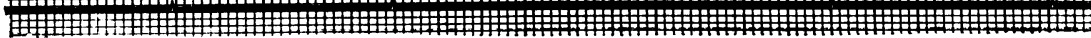

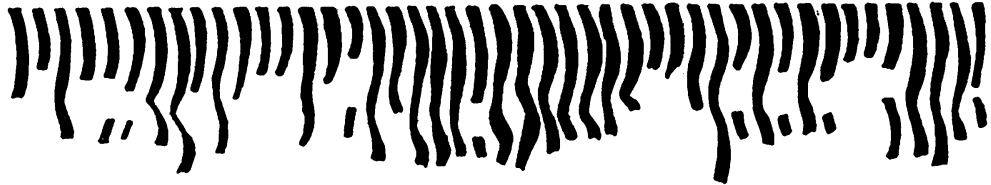
0.71
0.65
0.59
0.73
0.17
0.25

Fig. 2. An Electrocardiogram (Lead II) is Shown from a Case of Aortic Insufficiency in Which Macroscopic Capillary Pulsation Was Visible

Simultaneous cinematographic records of the capillaries at the nail fold were made. Synchronous points were ascertained by the technique described in figure 1 . Underneath the electrocardiogram are drawings of the visible portion of the arterial limb of the same capillary in all the exposures taken when this electrocardiogram was made. Each drawing is actually synchronous with the point in the electrocardiogram immediately above it without allowance for the probable transmission time.

The number of cinematographic exposures was 10 per second. The drawings were made from tracings which magnified the size of the capillary 350 times. The decimal numbers indicate the time in seconds after the onset of ventricular systole in each cycle at which blood was visible in the greatest length of the arterial limb.

time after the onset of ventricular systole. This time should correspond with that at which the heart beat produced its maximum effect in the periphery. The changes seen, however, did not fulfill these expectations (fig. 2, table 2). The time in seconds after the onset of ventricular systole at which the greatest length of the arterial limb 
was visible differed in the cycles illustrated in figure 2 from 0.17 to 0.73 second and in those shown in table 2 from 0.01 to 0.83 second. In some cycles the arterial limb was longest at the time one would expect cardiac systole to pump more blood into the capillaries, but in others this occurred at a later period. and in a few just before the onset of the next ventricular contraction. In many instances marked irregularity was seen during an individual cycle. The type of variation is well illustrated in figure 2. In cycle $I$ the length of the arterial limb was short at the beginning. It became longer, shortened again, and was longest immediately before the next ventricular complex.

TABLE 2

The time in seconds after the onset of the corresponding ventricular systole (1) at which the maximum diameter of the arterial and venous limbs occurred, and (2) at which the arterial limb exhibited its greatest length

\begin{tabular}{|c|c|c|c|}
\hline Cycle & Arterial & Venous & Longest arterial limb \\
\hline & seconds & seconds & seconds. \\
\hline I & 0.60 & 0.10 & 0.80 \\
\hline II & 0.51 & 0.21 & 0.01 \\
\hline III & 0.43 & 0.33 & 0.73 \\
\hline IV & 0.47 & 0.77 & 0.47 \\
\hline V & 0.29 & 0.29 & 0.59 \\
\hline VI & 0.31 & 0.21 & 0.01 \\
\hline VII & 0.65 & 0.35 & 0.35 \\
\hline VIII & 0.57 & 0.57 & 0.07 \\
\hline IX & 0.27 & 0.27 & 0.67 \\
\hline $\mathrm{x}$ & 0.69 & 0.19 & 0.29 \\
\hline XI & 0.83 & 0.43 & $0: 83$ \\
\hline XII & 0.21 & 0.11 & 0.21 \\
\hline
\end{tabular}

In cycle II the limb was also very variable, being long at the beginning and also towards the end. The amount of blood visible in the arterial limb in cycle III was greater than in the two previous cycles and remained approximately the same throughout. Cycle IV showed a progressive decrease throughout, while in cycle $\mathrm{V}$ the total length remained approximately the same except once near the beginning when it became longer; at other times small gaps in the stream took place. In cycle VI the limb presented a gap and then became much shorter but increased considerably at the middle and end, the length remaining about the same throughout these periods. 
Blood flow. The capillaries at the nail fold were studied by inspection over prolonged periods of time. In this condition the difficulty of keeping the capillaries under observation which has been described by previous authors is especially great as the finger usually moves with every pulse beat. By careful fixation of the finger the extent of this movement can be reduced to a minimum but even then it is necessary to focus very carefully all the time in order to see the flow clearly. Variations in flow took place continuously in the various capillaries. In the greater number these changes bore no relation to the pulse beat and resembled those seen in normal individuals. In a few, changes in the rate of flow were present for a short time which suggested pulsation but it was impossible to be sure that this was the mechanism involved.

\section{SUMMARY AND DISCUSSION}

These studies show that the diameter of the capillaries in cases of aortic insufficiency was constantly changing. The various capillaries differed in this respect and no two subjects were alike. The blood flow also was very variable. The type of change observed resembled that seen in normal individuals. In several instances the magnitude of the variations in the arterial limb was greater than was seen in normal subjects and in patients with heart disease without cardiac decompensation. The changes in the venous limb resembled those in normal subjects. The mechanism of the production of these changes is uncertain. The possible factors have been discussed in a previous paper (14). No evidence was found o pulsation in the capillaries of the nail fold although macroscopic pulsation was present in the vessels under the nail and in those behind the nail fold. The site chosen for observation is not the most suitable for displaying the phenomenon but is the only one at present available with our technique. It is possible that pulsation might be seen in the capillaries in a more favorable situation.

\section{CONCLUSIONS}

1. The calibre of the arterial and venous limbs of the capillaries at the nail fold has been investigated by means of cinematography in 12 cases of aortic insufficiency in which macroscopic capillary 
pulsation was present. Simultaneous electrocardiograms were made so that the relation of the capillary changes to the heart beat could be studied.

2. Variations in the diameter of the arterial and venous limbs took place continuously. The changes in the arterial limb in some subjects were more marked than those seen in normal individuals but the changes in the venous limb as a rule were not so marked as in the arterial and resembled those seen in the normal.

3. No evidence was present to indicate that pulsation due to the heart beat was present in the capillaries examined.

\section{BIBLIOGRAPHY}

1. Quincke, H., Berl. Klin. Woch., 1868, v, 357. Beobachtungen über Capillar und Venenpuls.

Quincke, H., Berl. Klin. Woch., 1890, xxvii, 265. Ueber Capillarpuls und centripetalen Venenpuls.

2. Herz, M., Wien. Klinik., 1896, xxii, 165. Der Puls der Kleinsten Gefässe: onychographische Untersuchungen.

3. Jürgensen, E., Zeit. f. klin. Med., 1918, lxxxvi, 410. Mikrokapillarbeobachtungen und Puls der Kleinsten Gefässe.

Jürgensen, E., Deut. Arch. f. klin. Med., 1920, cxxxii, 204. Mikrokapillarbeobachtungen: Ein Beitrag zur pathologischen Physiologie des Kreislaufssystems.

4. Freedlander, S. O., and Lenhart, C. H., Arch. Int. Med., 1922, xxix, 12. Clinical Observations on the Capillary Circulation.

5. Weiss, E., and Dieter, W., Zentralbl. f. Herz.- u Gefässkrankh., 1920, xii, 295. Die Strömung in den Kapillaren und ihre Beziehung zur Gefässfunktion.

6. Secher, K., Acta Med. Scand., 1922, lvi, 295. Klinische Kapillaruntersuchungen.

7. Fischl, F., Med. Klin., 1923, xix, 980. Kapillarbeobachtung am Lebenden.

8. Hisinger-Jagerskiöld, H., Acta. Med. Scand., 1924, lx, 7. Einige Untersuchungen des Kapillarpulses nach der Müller-Weiss' schen Methode.

9. Boas, E. P., Arch. Int. Med., 1922, xxix, 763. The Nature of the So-called "Capillary Pulse."

10. Sumbal, J. J., Heart, 1923, x, 271. The Vessels Concerned in Clinical "Capillary Pulsation."

11. B oas, E. P., Heart, 1924, xi, 57. Clinical "Capillary Pulsation."

12. Lewis, T., Heart, 1924, xi, 151. Studies of Capillary Pulsation with Special Reference to Vasodilatation in Aortic Regurgitation and Including Observations on the Effects of Heating the Human Skin.

13. Heimberger, H., Zeits. f. ges. exp. Med., 1925, xlvi, 519. Beiträge zur Physiologie der menschlichen Capillaren.

14. Crawford, J. Hamilton, and Rosenberger, H., Jour. Clin. Invest., 1926, ii, 343. Studies on Human Capillaries. I. An Apparatus for Cinematographic Observation of Human Capillaries.

15. Crawford, J. Hamilton with the assistance of H. Rosenberger, Jour. Clin. Invest., 1926, ii, 351. Studies on Human Capillaries. II. Observations on the Capillary Circulation in Normal Subjects. 